\title{
Frequent Loss of Heterozygosity at 1p36.3 and p73 Abnormality in Parathyroid Adenomas
}

Liang Shan, M.D., Ph.D., Qifeng Yang, M.D., Yasushi Nakamura, M.D., Ph.D., Misa Nakamura Ph.D., Akira Miyauchi, M.D., Ph.D., Masahiko Tsujimoto, M.D., Ph.D., Yukio Nakatani, M.D., Ph.D., Kenichi Wakasa, M.D., Ph.D., Ichiro Mori, M.D., Ph.D., Kennichi Kakudo, M.D., Ph.D.

Department of Pathology (LS, QY, YN, MN, IM, KK), Wakayama Medical University, Wakayama; Kuma Hospital (AM), Kobe; Division of Pathology (MT), Osaka Police Hospital, Osaka; Department of Pathology $(Y N)$, School of Medicine, Yokohama City University, Yokohama; and Department of Pathology (KW), Osaka City University Medical School, Osaka, Japan

Although $1 p$ is one of the most common loci showing loss of heterozygosity $(\mathrm{LOH})$ in primary parathyroid adenoma, fine mapping has not been previously examined. In this study, we analyzed LOH in 32 primary parathyroid adenomas using five microsatellite markers at 1 p36 (proximal-D1S507D1S450-D1S2893-D1S468-D1S243-distal). All cases were heterozygous for at least one marker. The frequency of LOH varied from $41.2 \%$ (D1S468) to $7.1 \%$ (D1S507) among the different markers. LOH was detected consistently in a group of nine adenomas $(28.1 \%, 9 / 32)$. A single region $(7 \mathrm{cM})$ showing a consistent LOH at $1 \mathrm{p36.3}$ was obtained that was flanked distally by D1S468 and proximally by D1S2893. Because the p73 gene is localized within this region and acts as a tumor suppressor gene, we examined the possible involvement of p73 in the development of parathyroid tumor. Allelic loss of p73 was identified in four adenomas $(25 \%, 4 / 16$ informative cases) that were all from the group of the nine adenomas with $\mathrm{LOH}$, but somatic mutation was not detected in the remaining allele. At the StyI polymorphism of Exon 2, four of the six adenomas with $\mathrm{LOH}$ at 1 p36 were heterozygous and expressed the GC allele. Of the six heterozygous adenomas without $\mathrm{LOH}, 4$ showed biallelic and 2 monoallelic expressions (GC allele). All adenomas mainly expressed the p73a isoform. $p 73$ protein was observed in five of the six adenomas with LOH and in two of the six adenomas without LOH. There were no differences in $\mathrm{p} 73$ pro-

Copyright (C) 2001 by The United States and Canadian Academy of Pathology, Inc.

VOL. 14, NO. 4, P. 273, 2001 Printed in the U.S.A.

Date of acceptance: September 6, 2000.

This work was supported in part by a Grant-in-Aid for Research Fellows of the Japan Society for the Promotion of Science for Young Scientists (No. 19980027), and Grant-in-Aid for Scientific Research (c) (No. 09670199). Address reprint requests to: Kennichi Kakudo, M.D., Ph.D., Department of Pathology, Wakayama Medical University, 811-1 Kimiidera, Wakayama City, Wakayama, 641-0012 Japan; e-mail: kakudo-k@mail.wakayama-med.ac.jp; fax: 073-446-4825. tein levels between the samples with and without LOH. In conclusion, a candidate gene for parathyroid tumorigenesis is present within a $7-\mathrm{cM}$ region at 1 p36.3, however p73 is unlikely to be the target of the LOH at $1 \mathrm{p36.3.}$

KEY WORDS: 1p36, Hyperparathyroidism, Loss of heterozygosity, Parathyroid neoplasia, p73.

Mod Pathol 2001;14(4):273-278

Parathyroid adenoma is one of the most common endocrine tumors, characterized by excessive secretion of parathyroid hormone (PTH) and enlargement of mostly one parathyroid gland. The molecular mechanism of parathyroid tumorigenesis is still poorly understood (1). MEN 1 gene abnormality has been found in only about $20 \%$ of the sporadic parathyroid adenomas. Cyclin D1/PTH gene rearrangement seems to be involved only in a small subset of these tumors, and p53 gene mutations also appear to be rare. To localize the gene responsible for parathyroid tumorigenesis, loss of heterozygosity (LOH) has been analyzed in various loci, and different frequencies of $\mathrm{LOH}$ have been identified $(2,3)$. For example, $\mathrm{LOH}$ at 1q21-32 (the locus for the hyperparathyroidism and jaw tumor syndrome), 3q (the locus of calcium-sensing receptor gene), 6q, 11q13 (the locus of MEN 1 gene), and $15 q$ has been detected in $18,10,30,38$, and $35 \%$ of adenomas respectively. Among the various loci, $1 \mathrm{p}$ is the one of the most frequent to show $\mathrm{LOH}$ in parathyroid adenomas. Takara et al. have revealed a $30 \%$ frequency of LOH at the D1S243 locus (4). Cryns et al. have shown a frequency of $36 \%$ at 1p32-pter (5). Williamson et al. have reported a $27 \%$ of $\mathrm{LOH}$ at 1p32-pter and mapped a candidate gene in the region flanked by D1S228 and D1S507 (6). 1 p36 is also interesting because other endocrine tumors, such as pheochromocytoma, medullary thyroid carcinoma, and anterior pituitary adenoma 
have also been demonstrated harboring LOH in this region (7). A potent tumor suppressor gene is considered to be located in the distal region of $1 \mathrm{p}$. However, its localization is controversial, and a fine mapping is still needed. To more precisely localize the tumor suppressor gene for parathyroid tumorigenesis at $1 \mathrm{p} 36$, we analyzed 32 parathyroid adenomas using microsatellite markers. We identified a consistent region of $\mathrm{LOH}$ that was flanked by D1S468 and D1S2893 and further analyzed whether p73 abnormality was associated with the tumorigenesis of parathyroid adenomas.

\section{MATERIALS AND METHODS}

\section{Patients and Tumor Materials}

Thirty-two patients with primary hyperparathyroidism were analyzed. All underwent parathyroidectomy because of hypercalcemia, elevated serum level of PTH, and single parathyroid enlargement. The patients' ages varied from 26 to 72 years (mean, 56 years). The male to female ratio was 5:27. All of the tumors were typical primary parathyroid adenoma based on the clinical and pathological features. They were considered to be sporadic because of the absence of any evidence of association with hereditary tumor either clinically or pathologically. Neither primary nor secondary parathyroid hyperplasia was included in this study.

\section{DNA Extraction and LOH Analysis}

Parathyroid tumor materials were either frozenpreserved $\left(-80^{\circ} \mathrm{C}, 23\right.$ samples) or formalin-fixed $(9$ samples). Peripheral blood leukocytes (PBL), muscular, or other nontumorous tissues from the same patients were used as control. One slice of fresh tumor tissue or three $10-\mu \mathrm{m}$ sections of the formalin-fixed, paraffin-embedded tumor tissue were used for DNA extraction. Tumor and control tissues were first digested by proteinase $\mathrm{K}$ for 24 to 48 hours, and then DNA was extracted using the QIAamp Tissue Kit (QIAGEN, Hilden, Germany; 8). DNA from blood samples was extracted using the QIAamp Blood Kit (QIAGEN). $\mathrm{LOH}$ was analyzed using five microsatellite markers mapped at 1p36: proximal-D1S507-D1S450-D1S2893D1S468-D1S243-distal. Primers flanking each of the markers were designed based on the information from Genethon Human Genetic Linkage Map (9). The primer sequences $\left(5^{\prime}-3^{\prime}\right)$ used were as follows. D1S507: AGGGGATCTTGGCACTTGG and CTCTAGGGTTTCTGGAAAATGCTG; D1S450: GCTCCAATGTCCAAGGG and GGGTACTCAGATGGCTGGT; D1S2893: TTCTGGACTTGCCAGTTTCC and GCCTTAGGGAC TATGTACT; D1S468: AATTAACCGTTTTGGTCCT and GCGACACACACTTCCC; and D1S243: CACACAGGCTCACATGCC and GCTCCAGCGTCATGGACT.
Genomic DNA was amplified for 35 cycles at $95^{\circ} \mathrm{C}$ for 45 seconds, $55-60^{\circ} \mathrm{C}$ for 30 seconds, and $72^{\circ} \mathrm{C}$ for 30 seconds in each cycle. Six microliters of the PCR product was mixed with same volume of loading buffer (99\% deionized formamide, 20 mM EDTA, 0.05\% xylene cyanol, and $0.05 \%$ bromphenol blue), denatured at $95^{\circ} \mathrm{C}$ for 5 minutes, and then plunged into ice immediately. The whole volume of the mixture was loaded onto a denaturing gel $(6 \%$ polyacrylamide gel containing $7 \mathrm{~m}$ urea and $32 \%$ formamide for the markers of D1S468, D1S2893, and D1S507; 10\% polyacrylamide gel containing only $32 \%$ formamide for the markers of D1S243 and D1S450). Electrophoresis was carried out under 300 constant volts for 5 hours at room temperature, and the gels were stained by silver staining using a PlusOne DNA Silver Staining Kit in a GeneStain Automated Gel Stainer (Pharmacia Biotech AB, Uppsala, Sweden). LOH was determined by comparing the polymorphic pattern of marker genotypes derived from analysis of normal and tumor DNA.

\section{Allelic Loss Analysis of p73 Gene}

Allelic loss of p73 gene was analyzed using the CT repeat-length polymorphism within Intron 9 of the p73 gene (10). PCR amplification was carried out for 35 cycles under the following conditions: $45 \mathrm{sec}-$ onds at $95^{\circ} \mathrm{C}, 30$ seconds at $55^{\circ} \mathrm{C}$, and 30 seconds at $72^{\circ} \mathrm{C}$ using the following primers: sense, $5^{\prime}-$ CCTCTTCCTCCCCTACCAAC-3' and antisense, 5'TAGGCGACAGAGCAAGACG-3'. The PCR product was examined on a $10 \%$ polyacrylamide gel containing $32 \%$ formamide, and the gel was silver stained as described above.

\section{RNA Extraction and RT-PCR-SSCP Analysis}

RNA was prepared from 20-30 mg of fresh tumor tissues using an RNeasy Kit (QIAGEN) and quantified by a spectrometry at $260 \mathrm{~nm}$. The RNA $(1.0 \mu \mathrm{g})$ was reverse-transcribed in a $20-\mu \mathrm{L}$ reaction volume at $42^{\circ} \mathrm{C}$ using the SuperScript Preamplification System (Life Technologies, Gaithersburg, MD) with 1 $\mu \mathrm{L}(0.5 \mu \mathrm{g})$ of $\mathrm{pd}(\mathrm{T}) 12-18$ primer. Two milliliters of the transcript was used to amplify the full cDNA sequence of p73 gene using three pairs of primers designed from exons: p73-1-sense (Exon 1), 5'AGCCGGGACGGACGCCGAT-3' and p73-6-antisense (Exon 6), 5'-GGTCATCCACATACTGCGAG-3' to amplify a 760-bp fragment from Exons 1 to 6; p73-5-sense (Exon 5), AGCACGTGACCGACGTCGTG-3' and p73-11-antisense (Exon 11), 5'-TTGTTCATGGGCGAGAGGAC-3' to amplify a 694-bp fragment from Exons 5 to 11; and p73-10-sense (Exon 10), 5'-AGCCACTGGTGGACTCCTAT-3' and p73-14-antisense (Exon 14), 5'-ATGGTCATGCGGTACTGCTC-3' to amplify a 475-bp fragment from Exons 10 through 14. The amplification was carried 
out for 35 cycles at $95^{\circ} \mathrm{C}$ for 45 seconds, $58^{\circ} \mathrm{C}$ for 30 seconds, and $72^{\circ} \mathrm{C}$ for 30 seconds using TaKaRa LA Tag with GC buffer (Takara, Otsu, Japan). Six milliliters of each PCR product was first electrophoresed on a $2 \%$ agarose gel to determine whether splice variants existed. Then each band was excised from the gel and extracted using QIAEX II Gel Extraction Kit (QIAGEN). The extracted band was treated overnight using 24 units of MvaI restriction enzyme (Takara). After purification and resuspension in 3 $\mu \mathrm{L}$ of water, the sample was mixed with the same volume of loading buffer and denatured for $5 \mathrm{~min}$ utes at $95^{\circ} \mathrm{C}$. The whole volume was applied onto a GeneGel Excel 12.5/24 gel (Pharmacia Biotech AB) and electrophoresed with 250 volts at $7^{\circ} \mathrm{C}$ on a GenePhor Electrophoresis Unit (Pharmacia Biotech $\mathrm{AB})$. The gel was silver stained, as described above. Using MvaI digestion, the 760-bp RT-PCR fragment was cleaved into four small fragments $(235,263,89$, and $173 \mathrm{bp}$ each, respectively), the 694-bp fragment was cleaved into four small fragments $(276,64,230$, and 224-bp, respectively), and the 475-bp fragment, into three small fragments $(40,249$, and $189 \mathrm{bp}$, respectively). If an abnormal migration band was identified, direct sequencing was carried out. As a control for the RT-PCR procedures, a 353-bp segment of human $\beta$-actin cDNA was amplified using the following primers: sense 5'-GCTCGTCGTCGACAACGGCTC-3' and antisense 5'-CAAACATGATCTGGGTCATCTTCTC-3' (Life Technologies). The PCR amplification was performed according to the manufacturer's instruction using $2 \mu \mathrm{L}$ of the transcript.

\section{Direct Sequencing}

To confirm the sequence of the RNA transcript, the RT-PCR fragments from one selected case were sequenced directly using the same sense and antisense primers. The RT-PCR products were first electrophoresed on a $2 \%$ agarose gel. Then the bands were excised from the gel, extracted using QIAEX II Gel Extraction Kit (QIAGEN), and further purified using StrataPrep PCR purification Kit (Stratagene, La Jolla, CA). One microliter of the solution was used for sequence reaction using the BigDye Terminator Cycle Sequencing Kit and the Applied Biosystems Model 310 Sequencer (Applied Biosystems). The DNA sequence of the RT-PCR generated fragments was compared with the registered cDNA sequence in the Genbank database (accession number Y11416).

\section{Allelic Expression Analysis}

Allelic expression was analyzed using the StyI polymorphism within Exon 2 ( $\mathrm{G}$ to $\mathrm{A}$ and $\mathrm{C}$ to $\mathrm{T}$ at Positions 4 and 14 of Exon 2 respectively, which give rise to GC and AT alleles). Three parallel sections were set: normal genomic DNA, tumor genomic DNA, and tumor cDNA. The primers used for amplification of a genomic DNA fragment containing the StyI polymorphism were as follows: p731-sense (an intron-specific primer), 5'-CAGGCCCACTTGCCTGCC-3'; and p73-2-antisense (Exon 2-specific primer), 5'-AGAGAGCTCCAGAGGTGCTC-3'. The primers used for amplification of a cDNA fragment were p73-1-sense and p73-2antisense. Six microliters of the PCR products (product concentration varied from 0.145 to 0.21 $\mu \mathrm{g} / \mu \mathrm{L})$ were digested with 20 units of StyI enzyme at $37^{\circ} \mathrm{C}$ overnight in a $50-\mu \mathrm{L}$ reaction volume. After purification, they were analyzed using the GeneGel Excel 12.5/24 Gel with silver staining as described above. Allele-specific expression of the p73 was determined by comparing the GC and AT alleles among the tumor cDNA and genomic DNA with normal genomic DNA.

\section{Western Blot Hybridization}

Tumor protein extracts were prepared using 250 $\mu \mathrm{L}$ of lysis buffer (40 mM HEPES (pH 7.4), 1\% Triton X100, 10\% glycerol, and $1 \mathrm{~mm}$ PMSF). The protein concentration was determined using the BCA Protein Assay Kit (Pierce, Rockford, IL). Eighty micrograms of the total protein from each sample was analyzed using a $10 \%$ sodium dodecyl sulfate-polyacrylamide gel electrophoresis and electroblotted onto a polyvinylidene difluoride membrane (Millipore, Bedford, MA). The membrane was incubated overnight with a goat polyclonal p73 antibody (1: 1000, C-20, Santa Cruz Biotechnology Inc., Santa Cruz, CA) and sequentially for 1 hour with horseradish peroxidase-coupled anti-goat IgG secondary antibody (1:3000, DAKO, Glostrup, Denmark). Reactive proteins were visualized using an ECL Western Blotting Analysis System (Amersham, Buckinghamshire, United Kingdom) according to the manufacturer's protocol.

\section{RESULTS}

Localization of the Candidate Gene Responsible for Parathyroid Adenomas

All cases were heterozygous for at least one microsatellite marker at $1 \mathrm{p} 36$. Different markers showed varied frequencies of LOH. The highest frequency of LOH was observed at D1S468 locus $(41.2 \%, 7 / 17)$ and the lowest frequency, at D1S507 $(7.1 \%, 1 / 14)$. The LOH frequencies at D1S243, D1S2893, and D1S450 were $21.4 \%$ (3/14), 25\% (4/ $16)$, and $25 \%$ (4/16), respectively. $\mathrm{LOH}$ was consistently observed in a group of nine individual adenomas $(28.1 \%, 9 / 32)$. In five adenomas, the loss 
involved the entire $1 \mathrm{p} 36$. In three adenomas, the distal region of $1 \mathrm{p} 36$ was lost, and in one adenoma, the proximal region of the loci was lost. As shown in Figures 1 and 2, the adenoma K43 at D1S243 locus, and the adenomas $\mathrm{H} 2, \mathrm{~K} 2$, and $\mathrm{O} 6$ at D1S450 locus still retained both alleles. However, all nine adenomas showed LOH at the loci D1S468 and D1S2893, indicating that a candidate tumor suppressor gene is located within the 7-cM interval flanked by D1S468 and D1S2893 at 1p36.3.

\section{Allelic Loss of the p73 Gene}

Of the 32 cases, 16 were heterozygous for the CT repeat length polymorphism within Intron 9 of $\mathrm{p} 73$. Allelic loss was observed in four adenomas $(25 \%$, $4 / 16$ ), and all four adenomas were from the group of the nine with LOH (Figs. 1 and 2). The other five tumors from the group were homozygous for $\mathrm{p} 73$ marker.

\section{Splice Variant Expression and Somatic Mutation of p73}

At present, six isoforms of p73 have been reported, and they are different in the $\mathrm{COOH}-$ terminal region (11). Considering the potential difference in their functions, we analyzed the expression of splice variants by RT-PCR amplification of p73 coding regions. Irrespective of the $\mathrm{LOH}$ status, all adenomas (six with $\mathrm{LOH}$ and six without LOH) predominantly expressed p73 $\alpha$ (Fig. 3). Direct sequencing of the RT-PCR-generated fragments confirmed the sequence of $\mathrm{p} 73 \alpha$. Some short bands were also observed by amplifying the $\mathrm{COOH}$ terminal region using the p73-10s and p73-14a primers. However, these bands were very weak compared with the band of $\mathrm{p} 73 \alpha$. We did not sequence these bands because they were not ex-

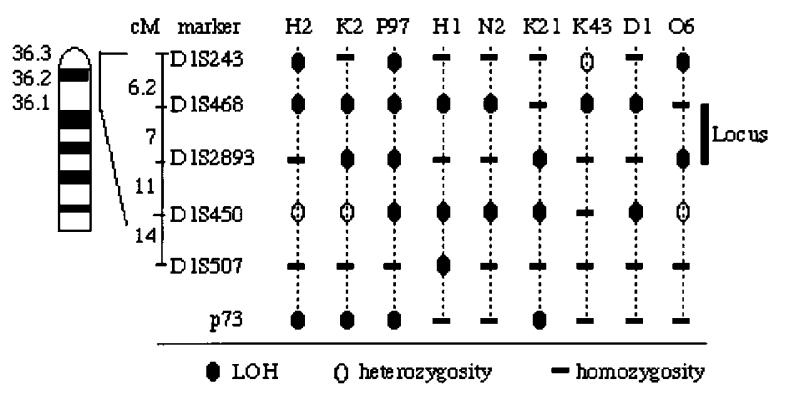

FIGURE 1. Summary of loss of heterozygosity (LOH) analysis of 1p36 and p73 in parathyroid adenomas. Microsatellite markers used and their genetic distances are listed at left, in order from distal (top) to proximal. Nine adenomas show $\mathrm{LOH}$ at one or more loci. A consistent LOH region is flanked by D1S468 distally and D1S2893 proximally with a genetic length of $7 \mathrm{cM}$, indicating that a putative tumor suppressor gene involved in the parathyroid tumorigenesis is located within this region. Analytic results of p73 are indicated below, and allelic loss is detected in four heterozygous adenomas, which also show LOH by other markers.

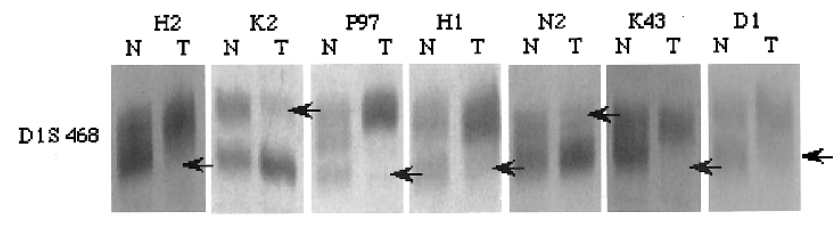

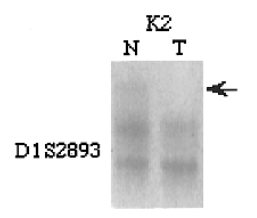
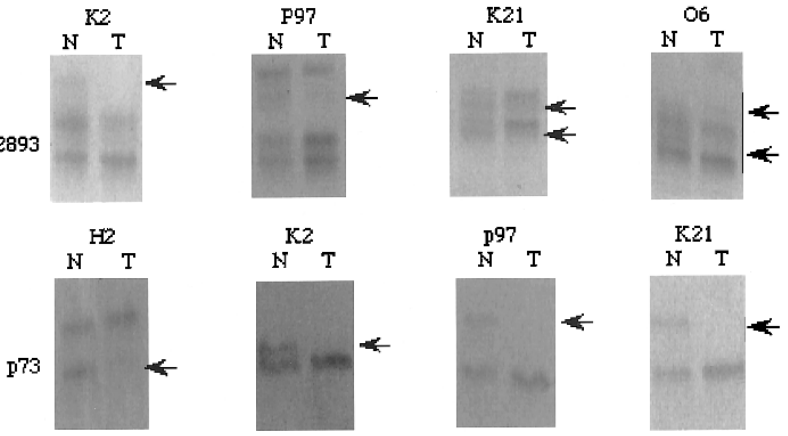

FIGURE 2. Loss of heterozygosity (LOH) at D1S468, D1S2893, and p73. At D1S468 locus, seven adenomas and at D1S2893, four adenomas have developed a LOH. Four adenomas also show LOH at p73. Deletion is indicated by an arrowhead. N, normal; $\mathrm{T}$, tumor.

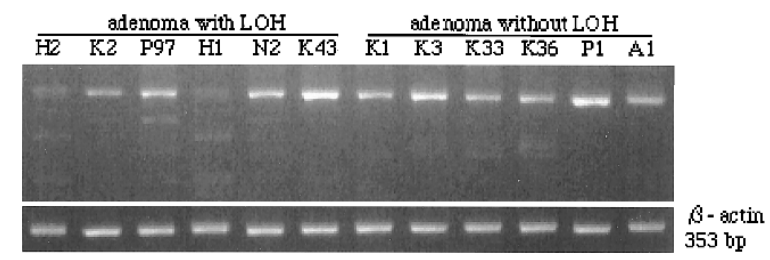

FIGURE 3. Representative demonstration of RT-PCR amplification of the $\mathrm{COOH}$-terminal region (475 bp). The upper strong band is confirmed to be $\mathrm{p} 73 \alpha$ by sequencing, indicating that parathyroid adenomas express predominantly $\mathrm{p} 73 \alpha$, irrespective of loss-ofheterozygosity status. Some unconfirmed, weak bands are also noted below the main band in some adenomas. RT-PCR amplification of human $\beta$-actin is used as a control.

pressed to a significant extent. By RT-PCR-SSCP analysis, we did not detect any somatic mutations.

\section{Allelic Expression of p73}

We were able to analyze six of the nine adenomas with $\mathrm{LOH}$. The remaining three adenomas with $\mathrm{LOH}$ were unsuitable because of absence of fresh tumor tissue. At the StyI polymorphic site, four of the six adenomas with $\mathrm{LOH}$ were heterozygous and expressed the GC allele. Six heterozygous adenomas without $\mathrm{LOH}$ were also studied as a comparative analysis, and of these samples, four showed biallelic and two showed monoallelic (GC allele) expressions.

\section{p73 Protein Expression}

Although $80 \mu \mathrm{g}$ of total protein from each sample was applied on the gel, only weak expression of the p73 protein was detected. We were unable to load more protein on the gel for analysis because of the limited amount of tumor tissue. Of the six adeno- 
mas with LOH, we detected p73 protein in five parathyroid adenomas. Another adenoma showed no identical band at $73 \mathrm{kDa}$. Of the six adenomas without $\mathrm{LOH}$, two expressed p73 protein, and four showed no expression. There was no obvious difference in the amount of expressed protein between adenomas with and without LOH (Fig. 4)

\section{DISCUSSION}

$1 p$ is a region with a high frequency of $\mathrm{LOH}$ in parathyroid adenoma; however, the frequency as reported in the literature varies greatly. In addition, the location of the LOH had not been precisely mapped. The reason for the variation in LOH frequency may be largely due to the use of only one or two microsatellite markers and these markers, which are widely dispersed on $1 \mathrm{p} .1 \mathrm{p} 36$ is an interesting region because it is one of the loci showing $\mathrm{LOH}$ in a variety of endocrine tumors. Therefore, we focused our analysis on $1 \mathrm{p} 36$. Although varied markers showed varied frequencies of $\mathrm{LOH}$ and the deletion regions were also different in different adenomas, we could map a 7 -cM region with a consistent deletion at $1 \mathrm{p} 36.3$. This region was flanked by D1S468 distally and D1S2893 proximally. A tumor suppressor gene that is inactivated in primary parathyroid adenoma, is strongly suggested to be present within this region. A number of potential candidate genes are located in the distal region of $1 p$, such as the Zinc Finger ZFM60, the developmental regulator gene Pax7, the helix-loop-helix protein Heir-1, the cell cycle regulator p58, the transcription factor E2F-2, TR2 gene, and p18 cyclindependent kinase inhibitor gene. Some of the genes in this region, such as p18 cyclin-dependent kinase inhibitor gene, have been ruled out as candidate genes; however, the role of many of these candidate genes still remains to be elucidated $(4,6,12)$.

p73 gene, with a significant homology to p53, is located just at the D1S468 locus of 1p36.3 (13). Much evidence also suggests that p73 acts as a tumor suppressor gene and is abnormally ex-

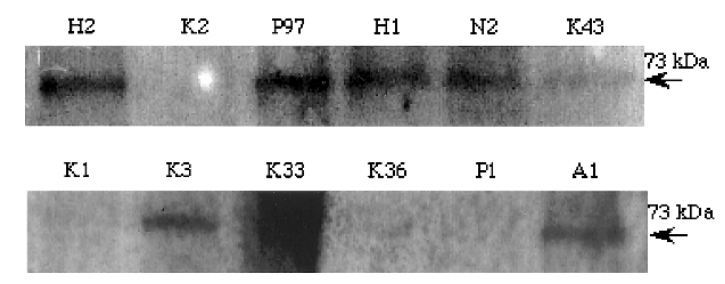

FIGURE 4. Western blot analysis of p73 protein. The upper shows six adenoma with loss of heterozygosity $(\mathrm{LOH})$ at $1 \mathrm{p} 36$, and the lower shows 6 without LOH. A total of $80 \mu \mathrm{g}$ of protein is applied from each sample. The p73 protein is identified in five adenomas with $\mathrm{LOH}(\mathrm{H} 2$, P97, H1, N2, and K43) and in two adenomas without LOH (K3 and A1). Evident difference for the amount of expressed protein is not observed between adenomas with and without LOH. pressed in many human tumors. For example, monoallelic expression has been reported in neuroblastoma (13), and transcriptional silencing has been identified in several types of hematological malignancies (14). In solid tumors, p73 is found to be overexpressed, an alteration that is considered to be related to carcinogenesis $(11,15,16)$. Given the localization and possible functions of p73 gene (17), we analyzed whether p73 was the target gene for parathyroid tumorigenesis. Using the CT repeat within Intron 9 of the p73 gene, we detected allelic loss of p73 in four parathyroid adenomas, with a frequency of $25 \%$. All four adenomas were from the group of nine with LOH at other markers. However, we did not find somatic mutation on the remaining allele in these adenomas. In the majority of other tumors examined in the literature, somatic mutations of p73 were also not detected $(18,19)$. As we compared the expression of p73 between adenomas with $\mathrm{LOH}$ and those without $\mathrm{LOH}$, we found that the adenomas with LOH expressed only the GC allele; however, monoallelic expression was also observed in the adenomas without LOH. Our findings are quite similar to the results from other studies that have identified both the biallelic and monoallelic expressions in solid tumors (20). On the protein level, only a weak expression was observed in both types of adenomas, and differences in expression were not observed between them. We had no evidence of p73 overexpression in parathyroid adenomas, as reported in some other tumors. This difference may be partially due to how expression was evaluated. Our results were based on the comparison of the p73 expression between adenomas with and without p73 allelic loss. Overexpression in some other reports is concluded based on the comparison between tumor tissue and corresponding normal tissue $(11,16)$. Tumor and normal tissue may vary in stroma that does not express p73. For example, in the mammary gland, stromal tissue is less in tumors than in normal mammary tissue, which may account for lower p73 expression in normal tissue. We did not analyze whether methylation is involved in the inactivation of the remained allele; however this seems unlikely because we could detect the mRNA and protein in these adenomas. Our results indicate that the p73 gene may be not the target of 1 p36.3 $\mathrm{LOH}$ in parathyroid adenomas, although allelic loss of the p73 is present. A similar conclusion ruling out p73 as a target gene was reached in studies of ovarian adenocarcinoma that harbor frequent $\mathrm{LOH}$ at 1 p36 (21, 22).

In conclusion, we localized a $7-\mathrm{cM}$ region with a consistent $\mathrm{LOH}$ in parathyroid adenoma. This region is flanked distally by D1S468 and proximally by D1S2893 at 1p36.3. p73 seems to be not the target of 1p36.3 LOH in parathyroid adenoma. Localization 
of the candidate gene will help in its isolation and characterization, ultimately leading to a better understanding of the molecular pathogenesis of parathyroid tumor.

\section{REFERENCES}

1. Kakudo K, Shan L. Recent advances in the molecular pathology of hyperparathyroidism. Endocr Pathol 1999;10:3-13.

2. Koshiishi N, Chong J-M, Fukasawa T, Ikeno R, Tanaka A, Kanazawa $\mathrm{K}$, et al. Microsatellite instability and loss of heterozygosity in primary and secondary proliferative lesions of the parathyroid gland. Lab Invest 1999;79:1051-8.

3. Farnebo F, Teh BT, Dotzenrath C, Wassif WS, Svensson A, White I, et al. Differential loss of heterozygosity in familial, sporadic and uremic hyperparathyroidism. Hum Genet 1997;99:342-9.

4. Tahara H, Smith AP, Gaz AD, Zariwala M, Xiong Y, Arnold A. Parathyroid tumor suppressor on $1 \mathrm{p}$ : analysis of the p18 cyclin-dependent kinase inhibitor gene as a candidate. J Bone Miner Res 1997;12:1330-4.

5. Cryns VL, Yi SM, Takara H, Gaz RD, Arnold A. Frequent loss of chromosome arm 1p DNA in parathyroid adenomas. Genes Chromosomes Cancer 1995;13:9-17.

6. Williamson C, Pannett AAJ, Pang JT, Wooding C, McCarthy $\mathrm{M}$, Sheppard MN, et al. Localisation of a gene causing endocrine neoplasia to a $4 \mathrm{cM}$ region on chromosome 1p35-36. J Med Genet 1997;34:617-9.

7. Mathew CGP, Smith BA, Thorpe K, Wong TZ, Royle NJ, Jeffreys AJ, et al. Deletion of genes on chromosome 1 in endocrine neoplasia. Nature 1987;328:542-6.

8. Shan L, Nakamura M, Nakamura Y, Inoue D, Morimoto S, Yokoi T, et al. Comparative analysis of clonality and pathology in primary and secondary hyperparathyroidism. Virchows Arch 1997;430:247-51.

9. Gyapay G, Morissette J, Vignal A, Dib C, Fizames C, Millasseau $\mathrm{P}$, et al. The 1993-94 Genethon human genetic linkage map. Nat Genet 1994;1993:7:246-339.

10. Ichimiya S, Nimura Y, Kageyama H, Takada N, Sunahara M, Shishikura T, et al. p73 at chromosome 1p36.3 is lost in advanced stage neuroblastoma but its mutation is infrequent. Oncogene 1999;18:1061-6.
11. Zaika AI, Kovalev S, Marchenko ND, Moll UM. Overexpression of the wild type p73 in breast cancer tissues and cell lines. Cancer Res 1999;59:3257-63.

12. Kwon BS, Tan KB, Ni J, Oh KO, Lee ZH, Kim KK, et al. A newly identified member of the tumor necrosis factor receptor superfamily with a wide tissue distribution and involvement in lymphocyte activation. J Biol Chem 1997;272:14272-6.

13. Kaghad M, Bonnet H, Yang A, Creancier L, Biscan J-C, Valent A, et al. Monoallelically expressed gene related to p53 at 1p36, a region frequently deleted in neuroblastoma and other human cancers. Cell 1997;90:809-19.

14. Corn PG, Kuerbitz SJ, van Noesel MM, Esteller M, Compitello $\mathrm{N}$, Baylin SB, et al. Transcriptional silencing of the p73 gene in acute lymphoblastic leukemia and Burkitt's lymphoma is associated with 5' CpG island methylation. Cancer Res 1999; 59:3352-6.

15. Chi S-G, Chang S-G, Lee C-H, Kim JI, Park J-H. Elevated and biallelic expression of p73 is associated with progression of human bladder cancer. Cancer Res 1999;59:2791-3.

16. Tokuchi Y, Hashimoto T, Kobayashi Y, Hayashi M, Nishida K, Hayashi S, et al. The expression of p73 is increased in lung cancer, independent of p53 gene alteration. Br J Cancer 1999;80:1623-9.

17. Perri P, Praml C, Savelyeva L, Pillmann A, Schwab M. Fine mapping of distal 1p loci reveals TP73 at D1S468. Cytogenet Cell Genet 1999;84:111-4.

18. Shishikura T, Ichimiya S, Ozaki T, Nimura $\mathrm{Y}$, Kageyama H, Nakamura $\mathrm{Y}$, et al. Mutational analysis of the p73 gene in human breast cancers. Int J Cancer 1999;84:321-5.

19. Nimura Y, Mihara M, Ichimiya S, Sakiyama S, Seki N, Ohira $\mathrm{M}$, et al. p73, a gene related to p53, is not mutated in esophageal carcinomas. Int J Cancer 1998;78:437-40.

20. Kovalev S, Marchenko N, Swendeman S, La Quaglia M, Moll UM. Expression level, allelic origin, and mutational analysis of the p73 gene in neuroblastoma tumors and cell lines. Cell Growth Differ 1998;9:897-903.

21. Codegoni AM, Bertoni F, Patregnani C, Marinetti E, D’Incalci M, Broggini M. Allelic expression of p73 in human ovarian cancers. Ann Oncol 1999;10:949-53.

22. Imyanitov EN, Birrell GW, Filippovich I, Sorokina N, Arnold J, Mould MA, et al. Frequent loss of heterozygosity at 1p36 in ovarian adenocarcinomas but the gene coding p73 is unlikely to the target. Oncogene 1999;18:4640-2. 